\title{
Discussion of "the effect of energy concentration of earthquake ground motions on the nonlinear response of RC structures” by H. Cao, M.I. Friswell
}

\author{
Abbas Moustafa ${ }^{*}$ \\ Department of Civil Engineering, Nagasaki University, Nagasaki 852-8521, Japan
}

\begin{abstract}
This discussion raises a few comments and questions on the paper by Cao and Friswell [1]. The authors consider an interesting problem on seismic response analysis of nonlinear structures. Specifically, the study examines the implication of the energy concentration of the adopted ground acceleration record on the nonlinear response of reinforced concrete structures. The paper employs the wavelet transform to characterize the energy content of the ground acceleration in time and frequency domains.
\end{abstract}

Keywords: energy; resonant acceleration; frequency content; inelastic response; RC buildings

\section{Comments and Questions}

The following comments are raised:

1. The literature presented on characterization of earthquake ground motions is inadequate.

The class of ground motions having resonance or pulse-like nature, and, thus concentrated energy, is well studied in the literature. For near-field records, this class of ground motions is known as pulse-like near-field ground motions with directivity effects resembling fault-parallel and fault-normal components (see, e.g., [2], reference [9] in the original paper). Acceleration pulses can also occur at sites located at large distance from the epicenter due to 
path and local soil effects. Housner and Hudson [3] showed that the March 18, 1957 Port Hueneme earthquake consisted essentially of a single pulse. Since energy was contained in one pulse, the damage caused by this earthquake was unusual for a moderate earthquake. They further concluded that if a pulse-like earthquake of larger magnitude could occur it would require a revision of engineering thinking with possible intensities of ground motions. Acceleration pulses were also observed during the 1966 Parkfield, 1971 San Fernando, and 1985 Mexico-city earthquakes [4]. Additionally, the paper by Anderson and Bertero tackled a very similar problem that is worth mentioning [4]. These authors examined the implications of adopting different ground acceleration records from the same earthquake at the same seismic region on the nonlinear structure response in the near-field region. They showed that the nonlinear response of frame structures under pulse-like ground motions (i.e., ground motions with concentrated energy) is particularly sensitive to the pulse duration relative to the fundamental period of the structure, and, also to the pulse acceleration relative to the yield resistance seismic coefficient of the structure. Furthermore, the works of Zahrah and Hall and Uang and Bertero on earthquake input energy and energy dissipated by inelastic structures represent early works on this subject that cannot be ignored $[5,6]$.

2. The paper addresses the effect of the selected ground motion on the response of RC buildings. It may be emphasized, however, that for nonlinear structures, a more realistic measure of the structural performance under ground motion is the damage index, see, e.g., 
$[7,8]$. Damage indices have been successfully used to assess the structural performance of RC structures under earthquake ground motions. In fact, the maximum displacement (or ductility) response is not a robust measure of the structure performance since structures get damaged due to not only maximum responses attained during ground shaking but also due to hysteretic energy dissipated by repeated yielding $[7,8]$.

3. The introduction section addresses the decomposition of earthquake records into components having non-overlapping frequency bands using the wavelet transform that is performed in section 2. It may be noted that Der Kiureghian and Crempien have performed a similar analysis using the Fourier transform for the 1971 Orion earthquake and estimated the contribution of each frequency bandwidth to the total intensity of the acceleration signal [9]. The study also developed one of the first probabilistic evolutionary models for the ground acceleration. The books by Priestley $[10,11]$ provide very useful information on nonstationary time series analysis in time and frequency domains. It is worth mentioning these basic works.

4. The normalization of records in terms of peak ground acceleration (PGA) is not appropriate. A more suitable criterion for normalization is the energy or intensity of the ground acceleration. For instance, the Arias intensity $\left(I=\left[\int_{0}^{\infty} \ddot{x}_{g}^{2}(t) d t\right]^{1 / 2}\right)$ can be adopted [12].

5. It is mentioned in page 294 that frame 1 is designed according to "the Code for Concrete Structures and Technical Specification for Concrete Structures of Tall Buildings”. It'd have 
been appropriate to add this reference. It is also noted that the frame structure considered has $24 \mathrm{~m}$ height and fundamental natural period of $1.02 \mathrm{~s}$. Tall structures are known to be of height greater than about $47 \mathrm{~m}$. Some researchers consider tall buildings for height $\geq 75 \mathrm{~m}$, see, e.g. $[13,14]$. Is the frame building designed as a tall structure ? (the paper implies so) and does the design code consider seismic effects? No information on design dead and live loads or on the material yield characteristics (e.g., yield strength and yield displacement) are provided.

6. As mentioned by the authors, the three acceleration records adopted for frame 1 are selected from thousands of records based on the work of Bommer and co-workers $[15,16]$. In fact, the selection strategy presented by Bommer and co-workers (also in seismic codes) is based on the earthquake magnitude, epicenter distance and local soil type beneath the structure. None of this information is discussed or provided in the paper. Table 1 summarizes this information. It is noted that the epicenter distance, an important parameter for selecting design records, is substantially different for the three records (12.99, 43.49 and $26.31 \mathrm{~km})$. For instance, the first record represents a near-field acceleration, while the second record is a far-field record. The same comment applies to the second set of records (see, Table 1). The discusser performed a search for earthquake records of magnitude between 6.53-7.36, epicenter distance of 12.90-43.50 km and type D local soil (alluvium) using PEER center [17]. The search led to 214 horizontal records (i.e., total of 107 
earthquakes). An additional search with magnitude of 6.50-7.00, epicenter distance of 10-20 $\mathrm{km}$ and same soil condition led to 66 horizontal records. The discusser presumes that the set of three records adopted in the original paper were selected for numerical illustrations and not through search of records based on magnitude and epicenter distance. The significant difference in magnitude and epicenter distance for the three records confirms this comment. Other information on record duration, intensity, peak ground acceleration and soil condition is also important. This information is also shown in Table 1 . As reported in $[15,16]$ seismic codes differ on number of records to be adopted and on specifying the records duration. This information is important to be mentioned. Note also that the second record of the first set of records (Taft in the original paper) represents one of the 1952 Kern County earthquake records measured at Taft Lincoln school.

7. A final comment is on the nonlinear response time histories presented in Figures 3 and 7. It is noticed that the structure response oscillates around zero and that permanent deformation is zero (although response is shown up to $t=30 \mathrm{~s}$, no significant difference can be expected to happen beyond $30 \mathrm{~s}$ since the strong phase of the ground accelerations occurs in the first $10 \mathrm{~s}$ ). This, in turn would imply that hysteretic energy dissipated by yielding is zero. The question is whether the ground motions level adopted is strong enough to drive the structure into the inelastic range? Comparison of responses in these figures with those presented in Fig. 9 of reference [8] in the original paper confirms this comment. The discusser presumes 
that either the yield strength of the structure was very high or the ground motions are not strong enough to drive the structure beyond its elastic limit, thus leading to linear response. As is well known, the time variation of inelastic structures' deformation differs from that for elastic structures. Unlike the elastic structure, the inelastic structure after it has yielded does not oscillate about its initial equilibrium position. Yielding causes the structure to drift from its initial equilibrium position and system oscillates around a new equilibrium position until this gets shifted by another yielding.

8. There are a few typing mistakes:

- The parameter $a$ mentioned in page 293 below Eq. (1) is not defined. The discusser presumes that this could be $m$.

- Reference [7] needs to be corrected to "Conte JP. Effects of earthquake frequency nonstationarity on inelastic structural response”.

\section{References}

[1] Cao H, Friswell MI. The effect of energy concentration of earthquake ground motions on the nonlinear response of RC structures. Soil Dyn Earthq Eng 2009; 29:292-299.

[2] Bray JD, Rodriguez-Marek A. Characterization of forward-directivity ground motions in the near-fault region. Soil Dyn Earthq Eng 2004;24:815-828.

[3] Housner GW, Hudson DE. The Port Hueneme earthquake of March 18, 1957. Bull Seism Soc Amer 1958; 48:163-168.

[4] Anderson JC, Bertero VV. Uncertainties in establishing design earthquakes. J Struct Eng 1987; 113(8):1709-1724.

[5] Zahrah TF, Hall WJ. Earthquake energy absorption in sdof structures. J Struct Eng 1984; 
110:1757-1772.

[6] Uang C-M, Bertero VV. Evaluation of seismic energy in structures. Earth Eng Struct Dyn; 1990; 19-77-90.

[7] Park YJ, Ang AH-S. mechanistic seismic damage model for reinforced concrete. J Struct Eng 1985; 111(4):722-739.

[8] Hatzigeorgiou GD, Beskos DE. Direct damage-controlled design of concrete structures. J Struct Eng 2007; 133(2):205-215.

[9] Der Kiureghian A, Crempien J. An evolutionary model for earthquake ground motion. Structural Safety 1989; 6:235-246.

[10] Priestley MB. Spectral analysis and time series. Vol. 1: Univariate series, Academic Press, London, 1981.

[11] Priestley MB. Non-linear and non-stationary time series analysis. Academic Press, San Diego, CA, 1988.

[12] Arias A. A measure of earthquake intensity: Seismic design of nuclear power plants, Cambridge, MA: MIT press, 1970:438-468.

[13] Smith BS, Coull, A. Tall building structures. John Wiley \& Sons, New York, 1991.

[14] Lew M, Naeim F, Hudson MB, Koring BO. Challenges in specifying ground motions for design of tall buildings in high seismic regions of the united states, $14^{\text {th }}$ World Conference on Earthquake Engineering, Beijing, October 12-17, 2008.

[15] Bommer JJ, Ruggeri C. The specification of acceleration time-histories in seismic design codes. Eur Earthq Eng 2002;16(1):3-17.

[16] Bommer JJ, Acevedo AB. The use of real earthquake accelerograms as input to dynamic analysis. J Earthq Eng 2004;8(1):43-91.

[17] Pacific Earthquake Engineering Research Center. 2005; "http://peer.berkeley.edu/smcat/search.html”.

[18] Consortium organizations for strong-motion observation systems. 1999-2007; “http://db.cosmos-eq.org/scripts/default.plx”. 
Table 1: Information on strong ground motion records $[17,18]$

\begin{tabular}{|c|c|c|c|c|c|c|c|c|}
\hline & $\begin{array}{l}\text { Earthquake } \\
\text { date }\end{array}$ & record & $\begin{array}{c}\text { Moment } \\
\text { Magnitude }\end{array}$ & $\begin{array}{c}\text { Epicenter } \\
\text { distance (km) }\end{array}$ & Recording station & $\begin{array}{c}\text { Duration } \\
(\mathrm{s})\end{array}$ & PGA (g) & $\begin{array}{l}\text { Arias Intensity } \\
\qquad\left(\mathrm{m} / \mathrm{s}^{1.5}\right)\end{array}$ \\
\hline \multirow{3}{*}{ 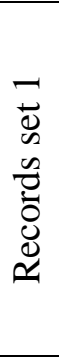 } & $\begin{array}{l}\text { Imperial Valles } \\
(1940-05-19)\end{array}$ & y NS & 6.95 & 12.99 & El Centro array \#9 & 40 & 0.31 & 3.26 \\
\hline & $\begin{array}{l}\text { Kern County } \\
(1952-07-21)\end{array}$ & N21E & 7.36 & 43.49 & Taft Lincoln school & 54.14 & 0.16 & 1.84 \\
\hline & $\begin{array}{l}\text { Imperial Valley } \\
(1979-10-15)\end{array}$ & N40W & 6.53 & 26.31 & $\begin{array}{c}\text { El Centro array \#10 } \\
\text { (Community hospital) }\end{array}$ & 36.98 & 0.22 & 2.05 \\
\hline \multirow{3}{*}{ 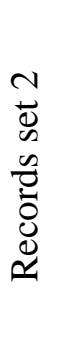 } & $\begin{array}{l}\text { Eureka } \\
(1954-12-21)\end{array}$ & N44E & 6.60 & 39.70 & Ferndale, CA-City Hall & 42.30 & 0.16 & 0.96 \\
\hline & $\begin{array}{l}\text { Kern County } \\
(1952-07-21)\end{array}$ & N42E & 7.36 & 88.39 & Santa Barbara & 75.39 & 0.09 & 1.16 \\
\hline & $\begin{array}{l}\text { Imperial Valley } \\
(1979-10-15)\end{array}$ & N45W & 6.53 & 19.81 & Holtville post office & 37.75 & 0.22 & 2.29 \\
\hline
\end{tabular}

